\title{
HUBUNGAN IMAJINASI DAN FAKTA DALAM STRUKTUR FABEL KARYA SISWA SMP MUHAMMADIYAH 05 SURAKARTA DAN SISWA SMP MUHAMMADIYAH PANGKALAN BUN
}

\author{
THE RELATIONSHIP OF IMAGINATION AND FACTS IN THE FABLE \\ STRUCTURE WRITTEN BY THE STUDENTS OF SMP MUHAMMADIYAH \\ 05 SURAKARTA AND SMP MUHAMMADIYAH PANGKALAN BUN
}

\author{
Yustika Krismoni, Markhamah \\ Universitas Muhammadiyah Surakarta \\ Ponsel: 089607792188; Pos-el: A310160005@student.ums.ac.id
}

\begin{abstract}
Abstrak
Artikel ini bertujuan untuk mendiskripsikan hubungan imajinasi dan fakta dalam struktur fabel, yang ditulis siswa dari dua sekolahan yang berbeda yaitu siswa SMP 5 Muhammadiyah Surakarta dan SMP Muhammadiyah Pangkalan Bun. Metode artikel ini menggunakan analisis struktural. Jenis penelitian artikel ini menggunakan penelitian deskriptif dengan pendekatan kualitatif. Teknik pengumpulan data yang digunakan dalam artikel ini adalah teknik analisis dokumen. Keabsahan data yang digunakan dalam artikel ini yaitu trianggulasi sumber data. Hasil artikel ini yaitu fakta yang terbanyak dari karangan siswa SMP 5 Muhammadiyah terdapat di struktur orientasi ada 8 , fakta di struktur komplikasi ada 6 , dan fakta di struktur resolusi hanya ada 1. Fakta yang terbanyak dari karangan siswa SMP Muhammadiyah Pangkalan Bun terdapat di struktur orientasi ada 7 fabel, fakta di struktur komplikasi ada 3, dan fakta di struktur resolusi hanya ada 2. Imajinasi yang terbanyak dari karangan siswa SMP 5 Muhammadiyah terdapat di struktur komplikasi ada 5, imajinasi di stuktur orientasi ada 2, dan imajinasi di struktur resolusi ada 4. Imajinasi yang terbanyak dari karangan siswa SMP Muhammadiyah Pangkalan Bun terdapat di struktur komplikasi ada 7 fabel, fakta di struktur orientasi ada 2, dan fakta di struktur resolusi hanya ada 1.Kemudian fabel yang imajinasinya terletak pada 3 struktur ada 2 fabel, selain itu ada 2 fabel yang hanya berisi fakta semua tidak ada imajinasinya.
\end{abstract}

Kata kunci: cerita hewan (fable); fakta; imajinasi; karangan siswa 


\begin{abstract}
This study aims to describe the relationship between imagination and facts in the fable structures, written by the students from two different schools, namely SMP 5 Muhammadiyah Surakarta and SMP Muhammadiyah Pangkalan Bun. This study uses structural analysis method and descriptive research with a qualitative approach. The data collection technique used in this article is the document analysis technique. The validity of the data used in this article is the triangulation of data sources. Results of this study shows that most facts from the composition of students of SMP 5 Muhammadiyah are in the orientation structure with 8 facts, the facts in the complication structure are 6, and the facts in the resolution structure is only 1. Most facts of the composition of the students of SMP Muhammadiyah Pangkalan Bun are found in the orientation structure with 7 fables, 3 facts of complications structure, and 2 facts of structure of resolution. Most imagination of the composition of the students of SMP 5 Muhammadiyah is in the complications structure with 5 imaginations, 2 imaginations of the orientation structure, and 4 imaginations of the resolution structure. Most imaginations of the compositiom of students of SMP Muhammadiyah Pangkalan Bun are in the complications structure with 7 fables, 2 facts of the orientation structure, and one fact in the resolution structure.. Then, there are 2 fabels whose imagination is located in the 3 structures. In addition, there are 2 fables that only contain facts without imagination.
\end{abstract}

Keywords: animal stories (fables); facts; imagination; student essays

\section{Pendahuluan}

Fabel merupakan cerita khayalan dan bukan kisah nyata. Menurut Nurgiyantoro (2005:190), fabel atau cerita binatang adalah salah satu bentuk cerita (tradisional) yang menampilkan binatang sebagai tokoh cerita. Binatang dalam tokoh fabel dapat berpikir, berbicara, berperilaku layaknya seperi manusia. Saat membuat karangan fabel, siswa akan menggunakan imajinasinya untuk merangkai cerita dan menghasilkan fabel yang menarik untuk dibaca. Menurut Scott (dalam
Al-Ma'ruf (2017:43) imajinasi merupakan penggambaran anganangan dalam karya sastra. Penciptaan gambaran dalam kata-kata untuk mendiskripsikan sesuatu sehingga pembaca dapat membayangkan halhal dalam cerita yang mengandung imajinasi atau khayalan. Penggambaran angan-angan tersebut membuat lebih hidup gambaran dalam pikiran dan penginderaan serta untuk menarik perhatian pembaca. Jenis imajinasi ada dua yaitu imajinasi verbal dan imajinasi visual. Imajinasi verbal adalah imajinasi 
yang diproses oleh otak kiri dan terbentuk dari kumpulan kata-kata dalam pikiran manusia. Sedangkan imajinasi visual adalah imajinasi yang diproses otak kanan, berbentuk gambar-gambar dalam mata pikiran manusia.

Selain imajinasi, di dalam fabel juga ditemukan fakta-fakta cerita yang dapat dihubungkan dengan struktur fabel. Fakta merupakan informasi yang terkait dengan aspek kehidupan seseorang yang bersifat nyata. Penelitian ini bertujuan untuk menjelaskan hubungan dan fakta dalam struktur fabel. Perilaku atau tingkah laku yang dimiliki hewan dalam cerita fabel akan dianalisis, kemudian dihubungkan dengan imajinasi dan fakta yang terletak di salah satu struktur fabel. Tidak semua imajinasi dan fakta terletak pada satu struktur yang sama, tetapi ada fabel yang letak imajinasi dan faktanya terletak di struktur yang berbeda. Misalnya, fabel Kelinci dan Kura-kura yang mempunyai 2 fakta, fakta pertama terletak di orientasi dan fakta ke 2 terletak di komplikasi. Kemudian imajinasinya terletak di orientasi karena Kura-kura bertanya kepada Kelinci saat bertemu di hutan. Fokus artikel ini akan menjelaskan tentang hubungan imajinasi dan fakta dalam struktur fabel.

Berikut ini, beberapa penelitian tentang hubungan fakta dan imajinasi dalam struktur fabel yang telah dilakukan. Penelitian yang dilakukan oleh Bahri (2014) yang berjudul “Analisis Struktural Fabel Tegodek dait Tetuntel: Representasi Perilaku dalam Masyarakat Sasak" menunjukkan bahwa tokoh Godek cenderung menyampaikan informasi yang tidak sesuai dengan fakta, sedangkan tokoh Tuntel menyampaikan fakta sesuai dengan apa yang telah terjadi. Cara penyelesaian permasalahan menunjukkan tokoh Godek lebih cenderung mengambil alih, sedangkan tokoh Tuntel cenderung menerima seadanya.

Penelitian yang dilakukan oleh Putri (2017) yang berjudul "Struktur dan Makna Cerpen Si Rubbah Gong Karya Niimi Nankichi” menyatakan bahwa untuk mengetahui maknanya kita harus membaca keseluruhan isi cerpen dan memahami strukturnya, 
sehingga dapat memunculkan pesanpesan moral yang dapat mendidik pembacanya terutama anak-anak. Cerita anak perlu digunakan untuk mempengaruhi mental anak secara alami dan untuk menanamkan emosi serta cara berfikir anak. Di dalam fabel harus ada nilai-nilai moral yang sesuai dengan keadaan psikologi anak dan anak tersebut harus bisa memahami ceritanya. Dengan adanya hasil seperti itu, disarankan untuk semua siswa, jika ingin memahami suatu makna dalam sebuah cerita mereka harus membaca keseluruhan cerita tersebut.

\section{Landasan Teori}

Menurut Halida (2011:46), fabel merupakan teks yang berisi tentang ilmu mendidik atau pengajaran yang sering disebut dengan unsur didaktik. Melalui tokoh-tokoh dalam fabel tersebut unsur didaktik akan muncul secara eksplisit maupun implisit. Fabel dibangun dari cerita-cerita yang mengandung fakta dan hal-hal yang merupakan imajinasi.

Menurut Sibua dan Iskandar (2016:356), fakta merupakan suatu kejadian yang benar-benar terjadi, dapat dilihat, diraba, bahkan dirasakan oleh setiap orang. Fakta juga bisa dikatakan sebagai informasi yang terkait dengan aspek kehidupan seseorang yang bersifat nyata. Ciriciri fakta dapat dijabarkan sebagai berikut ini: (1) dilihat dari isi, fakta harus sesuai dengan kenyataan, (2) dilihat dari kebenaran, fakta harus benar-benar sesuai dengan kenyataan yang telah terjadi, (3) cenderung deskriptif dan apa adanya jika dilihat dari pengungkapan fakta, dan (4) cenderung induktif jika dilihat dari penalaran.

Menurut Scott (dalam Al-Ma'ruf (2017:43), imajinasi merupakan penggambaran angan-angan dalam karya sastra. Penggambaran anganangan tersebut membuat lebih hidup gambaran dalam pikiran dan penginderaan serta untuk menarik perhatian pembaca. Menurut Nasution (2018:23), teks fabel mempunyai struktur yang terdiri atas (1) Orientasi adalah bagian awal yang berisikan tentang pengenalan tokoh, latar tempat suasana, (2) Komplikasi yaitu tokoh dalam cerita mulai berhadapan dengan masalah 
yang muncul, (3) Resolusi adalah bagian pemecahan masalah dalam cerita, dan (4) Koda adalah perubahan pada tokoh dan amanat yang dapat diambil dalam cerita tersebut.

Teori yang dipakai dalam artikel ini adalah teori kritik strukturalisme, yaitu mengidentifikasi struktur fabel yang dihubungkan dengan imajinasi dan fakta fabel yang dibuat siswa. Menurut Pradopo (2003:54), bahwa dengan adanya unsur-unsur pembangun dalam karya sastra yang saling berkaitan, maka kita dapat memahami strukturnya sebagai suatu kesatuan yang bulat dan untuk memahami maknanya kita harus mengkaji karya sastra berdasarkan struktur. Karangan fabel ini ada hubungannya dengan imajinasi dan fakta dalam fabel.

\section{Metode Penelitian}

Jenis penelitian ini menggunakan penelitian deskriptif dengan pendekatan kualitatif. Menurut Syamsuddin dan Damaianti (2006:74), pendekatan kualitatif adalah pendekatan yang penting untuk memahami suatu fenomena sosial dan perspektif individu yang diteliti. Tujuan pokoknya adalah menggambarkan, mempelajari, dan menjelaskan fenomena itu. Menurut Sukardi (dalam Arsyad, dkk (2017:54), penelitian deskriptif merupakan metode penelitian yang digunakan untuk menggambarkan atau mendeskripsikan dengan lengkap sesuai dengan peristiwa, keadaan, objek yang sesuai dengan kenyataan dan dijelaskan dengan baik secara runtut melalui kata-kata. Peneliti berusaha untuk menjelaskan hubungan imajinasi dan fakta dalam struktur fabel karangan siswa.

Penelitian ini dilaksanakan di dua sekolah yang berbeda yaitu di SMP Muhammadiyah 5 Surakarta, tepatnya di Jalan Slamet Riyadi No. 443, Pajang, Kecamatan Laweyan, Kota Surakarta, Jawa Tengah (571146) dan di SMP Muhammadiyah Pangkalan Bun, tepatnya di Jalan Jendral Sudirman No.13A Kelurahan Sidorejo, Kecamatan Arut Selatan, Kotawaringin Barat, Pangkalan Bun (74111), Kalimantan Tengah.

Teknik pengumpulan data yang digunakan dalam penelitian ini 
adalah teknik analisis dokumen. Teknik analisis dokumen adalah teknik yang digunakan untuk menganalisis isi dokumen yang berupa fabel hasil karangan siswa, dengan mengumpulkan data-data yang sesuai. Data ini dikumpulkan dengan memberikan tugas kepada siswa untuk menulis karangan berupa fabel. Data yang sudah terkumpul kemudian dianalisis dan dideskripsikan sesuai dengan masalah yang sedang diteliti.

Penelitian ini menggunakan metode teknik analisis struktural, yaitu mengidentifikasi struktur wacana teks fabel yang dibuat siswa kelas VII di SMP 5 Muhammadiyah Surakarta dan di SMP Muhammadiyah Pangkalan Bun. Sesuai yang dikemukakan Pradopo (2003:54) bahwa dengan adanya unsur-unsur pembangun dalam karya sastra yang saling berkaitan, maka kita dapat memahami strukturnya sebagai suatu kesatuan yang bulat dan untuk memahami maknanya kita harus mengkaji karya sastra berdasarkan strukturnya sendiri.

Keabsahan data yang digunakan dalam penelitian ini yaitu trianggulasi sumber data. Menurut Rahardjo (2010), triangulasi sumber data adalah mencari kebenaran informasi dengan menggunakan metode dan sumber perolehan data. Pengumpulan data dari berbagai macam data yang saling berbeda namun metode yang digunakan sama, karena data dicek dengan satu teori.

\section{Pembahasan}

Hasil analisis data struktur wacana fabel ini, diambil dari 4 kelas yaitu kelas VII A, B, C, dan D di SMP Muhammadiyah 5 Surakarta. Jumlah siswa untuk masing-masing kelas yaitu 14, 28, 31, dan 29. Dari banyaknya data tersebut yang digunakan untuk analisis hanya 10 data dari 4 kelas tersebut. Data yang diambil dari kelas A ada 5, kelas B ada 2, kelas C ada 3, dan kelas D tidak ada. Data ini dipilih karena di dalam karangan tersebut terdapat beberapa variasi struktur fabel yang dibutuhkan peneliti untuk menganalisis karangan tersebut. Sedangkan data di SMP Muhammadiyah Pangkalan Bun, ada 
1 kelas yang digunakan untuk pengambilan data yaitu kelas 7B. Data dari 1 kelas tersebut tidak digunakan semua, hanya diambil 10 data dari keseluruhan siswa yang ada di kelas 7B. Pemilihan data ini dilakukan karena di dalam karangan tersebut terdapat beberapa variasi struktur fabel yang dibutuhkan sesuai dengan judul penelitian ini. Kemudian data dari 2 sekolahan yang berbeda itu dianalisis dalam penelitian ini.

\section{a. Contoh Fabel yang berisi fakta dan imajinasi dari siswa SMP 5 \\ Muhammadiyah Surakarta}

\section{Kelinci dan Kura-kura}

Pada suatu hari hiduplah seekor Kelinci dan Kura-kura di sebuah hutan besar di daerah Kalimantan. Pada suatu ketika si Kelinci sedang bersantai-santai di bawah pohon dan Kura-kura pun datang menemui Kelinci. Lalu Kurakura bertanya, "Hay Kelinci sedang apa kamu di sini? Kelinci pun menjawab "hai Kura-kura aku disini sedang bersantai-santai". Kelinci pun bertanya kembali kepada Kura-kura. "Apa yang kamu lakukan di sini Kura-kura?" Kura-kura menjawab" aku disini hanya ingin berjalan-jalan saja". Setelah itu Kura-kura pergi meninggalkan Kelinci. Keesokan harinya Kelinci menemui Kura-kura di rumahnya dan apa yang terjadi di rumah Kura-kura? ternyata di rumah Kura-kura ada seekor Harimau ganas yang akan menerkam Kura-kura. Kelinci pun khawatir dan langsung menolongnya. Kelinci yang sedang menolong Kura-kura pun ikut diterkam oleh Harimau lalu kedua binatang itu mati diterkam oleh Harimau ganas.

Amanat: Berbuat baiklah kepada semua makhluk, jika kamu butuh bantuan kamu juga dibantu orang lain.

Fabel Kelinci dan Kura-kura mempunyai fakta, bahwa hutan itu merupakan tempat tinggal binatang diantaranya Harimau. Walaupun tidak semua hutan ada Harimaunya. Hutan itu adalah hutan di daerah Kalimantan. Hal ini termasuk fakta karena menyebut Hutan yang ada di daerah Kalimantan. Fakta selanjutnya bahwa Harimau adalah binatang buas atau ganas. Harimau itu menerkam Kelinci dan Kura-kura sehingga Kelinci dan Kura-kura mati. Binatang juga membutuhkan makan hal ini berhubungan dengan kebutuhan hidup, agar mereka bisa bertahan hidup. Fabel ini ditulis berdasarkan fakta dan opini. Fakta yang dimaksud disini bahwa Harimau itu binatang yang ganas yang dibuktikan dengan tindakannya 
menerkam Kelinci dan Kura-kura. Fakta ini dipadu dengan imajinasi yakni imajinasi dengan percakapan antara Kelinci dan Kura-kura, yang digambarkan bahwa keduanya bercakap-cakap layaknya manusia. Imajinasi ini diawali dengan pertanyaan Kelinci kepada Kura-kura dan dilanjutkan dengan jawaban kura-kura yang menyatakan Kurakura itu sedang bersantai. Kelinci yang menolong Kura-kura yang bertujuan untuk melindungi Kurakura dari serangan Harimau. Hal itu dikatakan sebagai imajinasi karena secara faktual kedua binatang itu, pastilah tidak akan bisa melawan Harimau.

\section{Nasehat Burung Kenari}

Pada suatu hari seorang Gagak sedang membaca buku cerita dan akhirnya bertemu dengan burung Kenari. Burung Kenari menasehati burung Gagak bahwa kalau sedang baca jangan terlalu dekat. "Wahai si gagak jika engkau sedang membaca, janganlah terlalu dekat" kata si burung Kenari itu. Dan si Gagak tidak menjawab karena ia terlalu asyik membaca bukunya. "Hai Gagak jawab dong!" Tegas burung Kenari itu. "Emang kenapa burung Kenari?" Kata si Gagak itu. "Jika kau membaca dengan dekat mata kamu akan merah" kata burung kenari.
Kemudian si Gagak mengeluh "Aduh.. mataku sakit". Saat itu si burung Gagak menangis terus hingga matanya sampai merah sekali. Burung Kenari pun datang dengan berkata "wahai si burung Gagak mata kamu kenapa?" Gagak pun menjawab, "mataku merah karena aku baca dengan terlalu dekat. Aku menyesal" dengan menangis. "Makanya kalau dikasih tahu itu jangan membangkang! Kata si burung kenari. "Iya maafkan aku, Aku sangat menyesal" kata si Gagak. "Aku panggil si Bangau ya, biar kamu bisa diobatin sama si Bangau" kata Kenari dengan lemah lembut.

Kemudian Bangau datang," kenapa dengan matamu Gagak?" kata si Bangau. "Aku sakit mata karena aku baca buku terlalu dekat" Gagak menjelaskan kepada Bangau. Lalu mata Gagak diteteskan tes mata agar cepat sembuh. "Coba buka matamu" kata si Bangau. "yey mataku sembuh" kata si Bangau dengan senang. "Kamu lain kali kalau baca jangan terlalu dekat nanti mata kamu sakit lagi". "Ok Bangau, Terima kasih ya" kata Bangau. Akhirnya mata si Gagak tidak merah lagi. Jadi, lain kali jika mau baca jangan terlalu dekat.

Faktanya yaitu jika kita membaca buku terlalu dekat dapat mengakibatkan mata sakit. Jarak ketika kita sedang membaca minimal $30 \mathrm{~cm}$. Sedangkan imajinasinya Burung Gagak yang bisa membaca dan Bangau yang mengobati mata Gagak menggunakan tes mata. Hubungan fakta dan imajinasi 
pada teks analisis fabel tersebut memiliki hubungan antara satu dengan yang lainnya yaitu dapat dilihat dari letak fakta dan imajinasinya. Letak fakta terletak di Orientasi sedangkan imajinasinya terletak di Resolusi karena Bangau dapat memecahkan masalah dengan cara mengobati si Gagak. Cerita di atas tidak logis karena cerita ini hanya berupa impian-impian belaka yang merupakan imajinasi penulis. Misalnya, burung yang bisa membaca buku dan mampu mengobati temannya dengan cara menetes matanya menggunakan tes mata.

\section{Rusa dan harimau}

Pada suatu hari, ada Rusa yang sedang mencari makan di daerah pinggir danau. Rusa hendak memakan rumput tetapi ada suara auman Harimau. Kemudian Rusa ketakutan karena ada suara auman Harimau begitu keras. Karena adanya suara Harimau semakin dekat. Rusa lari ke dalam hutan yang penuh pepohonan. Semakin dalam semakin gelap, Rusa semakin takut. Kemudian ada suara auman Harimau lagi di balik semak-semak. Harimau muncul di depan Rusa tersebut sehingga Rusa pun panik untuk melarikan diri. Harimau pun mengejar Rusa tersebut. Harimau semakin dekat di belakangnya. Sehingga Rusa terjatuh karena tersandung batu. Setelah jatuh terus akan diterkam Harimau, sambil berkata "tolong" Rusa pun berteriak keras. Tidak ada yang mendengar suara Rusa tersebut. Harimau pun sambil berkata tamatlah Rusa tidak ada yang mendengar suara kamu. Sekarang ada ucapan terakhir apa, untuk terakhir kalinya? Rusa pun menjawab "ya". Harimau berkata "apa ucapan terakhir kamu?" Rusapun sambil menangis dan berkata aku sayang Ayah dan Ibu. Kemudian ia pun mati dan dimakan harimau tersebut.

Fabel ini hanya mempunyai fakta, bahwa Rusa mencari makan karena binatang juga membutuhkan makan untuk bertahan hidup, Rusa menangis, Rusa tersandung batu lalu berteriak keras meminta tolong. Cerita di atas dapat diterima oleh akal karena fakta dalam fabel terebut menjelaskan bahwa Rusa atau hewan lainnya juga membutuhkan makan dan mereka harus mencari makan untuk memenuhi kebutuhan hidupnya. Serta binatang juga bisa merasakan sakit seperti halnya manusia juga bisa merasakan sakit. Fakta dalam analisis fabel tersebut terletak pada struktur Orientasi dan Komplikasi karena saat Rusa di dalam hutan, ia bertemu dengan Harimau yang kelaparan dan ingin memangsa Rusa. 


\section{Semut dan Merpati}

Pada zaman dahulu ada seekor burung Merpati. Suatu ketika, burung tersebut bingung karena makanan yang ada di sarangnya sudah habis. Lalu burung Merpati itu pergi untuk mencari makanannya dan anak burung tersebut ditutupi dengan serabut, kemudian burung Merpati langsung pergi mencari makanan di tempat yang jauh.

Pada hari itu burung Merpati harus mencari minuman untuk anaknya terlebih dahulu, setelah sekian lama akhirnya burung Merpati itu menemukan sungai yang jernih, tetapi ada seekor Semut yang tenggelam di sungai tersebut. Merpati pun berkata "Astaga itu ada seekor Semut yang tenggelam. Aku harus menolongnya". Merpati pun harus mengambil daun yang besar utuk menolong Semut tersebut. Sudah sekian lama, Merpati pun menemukan daun dan bergegas untuk menolong Semut tersebut.

Sesampai di sungai Merpati itu meletakkan daun itu disungai, lalu Semut itu naik ke daun tersebut lalu langsung mendarat ke tepi sungai. Semut pun langsung berkata "terima kasih Merpati, untung kau ada, kalau tidak aku bisa mati tenggelam", Merpati pun berkata "ya sama-sama, aku pergi dulu ya" Semut berkata lagi "ya, terima kasih".

Sudah sekian lama Merpati tersebut menemukan makanan, tetapi ada seorang pemburu yang membawa panah untuk memburu. Pemburu itu menemukan seekor burung Merpati dan itu adalah sasaran pemburu tersebut. Lalu, seekor semut itu melihat pemburu itu memanah Merpati tersebut, Semut pun berkata "Merpati akan dipanah, aku harus bergegas untuk menolongnya!", Semut pun langsung beraksi.

Faktanya Burung Merpati mencari makan karena binatang juga membutuhkan makan untuk bertahan hidup dan ada pemburu yang sedang menangkap burung Merpati. Di dunia nyata juga banyak ditemui hal seperti ini. Sedangkan imajinasinya Semut dan Merpati yang melakukan pembicaraan, seakan-akan mereka dapat berbicara padahal hewan tidak bisa berbicara.

Hubungan fakta dan imajinasi pada teks analisis fabel tersebut dapat dilihat dari letak fakta dan imajinasinya. Letak fakta pertama terletak di Orientasi karena fabel ini awal ceritanya menceritakan "Burung Merpati yang sedang mencari makan". Kemudian fakta kedua terdapat di komplikasi yaitu mulai munculnya masalah yang ditandai dengan tertangkapnya Merpati oleh sang pemburu hutan. Sedangkan imajinasinya terletak di bagian komplikasi dan resolusi. Cerita ini tidak logis karena terdapat pembicaraan antar hewan yang berupa impian-impian belaka dan merupakan imajinasi penulis. 


\section{b. Contoh fabel yang berisi fakta} dan imajinasi dari siswa SMP

\section{Muhammadiyah Pangkalan \\ Bun}

\section{Si Burung Cawi dan Burung Elang}

Pada zaman dahulu hiduplah seekor Burung Cawi yang sangat cantik. Dia juga memiliki suara yang merdu, hewan-hewan di hutan pun menyukai Burung Cawi. Setiap hari mereka berkumpul di hutan, tempat Cawi tinggal. Mereka ingin mendengarkan suara Cawi. Mendengar kabar itu, si Elang pun ikut untuk mendengarkan suara merdu Cawi. Hewan-hewan tersebut sangat senang, ketika si Cawi bernyanyi dengan gembira.

Keesokan harinya, hewanhewan di hutan sepakat untuk menjadikan si Cawi Putri Rimba. Dengan kabar itu si Elang sangat iri kepada si Cawi, dia pun pergi untuk meninggalkan tempat itu. Kemudian si Elang ingin berbuat jahat kepada si Cawi. Si Harimau datang untuk membantu menyingkirkan si Cawi menjadi putri Rimba. Keesokan harinya hewan-hewan di hutan termasuk Elang berkumpul untuk menemui si Cawi putri Rimba. Si Cawi pun bernyanyi untuk hewanhewan di hutan. Tiba-tiba ada dua ekor Rusa berlari-lari untuk menemui si Cawi kalau rumahnya terbakar. Si Elang tau bagaimana cara untuk menyingkirkan si Cawi menjadi putri Rimba. Si Elang pun pergi meninggalkan tempat tersebut, kemudian si Elang memanggil Harimau untuk menyingkirkan si Cawi. Si Elang berencana untuk memasukan si Cawi ke rumah Rusa yang terbakar kemarin dan berpurapura ada emas di dalamnya kemudian rencana itu di setujui oleh Harimau. Keesokan harinya si Elang dan Harimau menemui si Cawi di rumah. Di dalam rumah Cawi hanya ada si Kancil. Si Elang menghasut si Cawi untuk pergi bersamanya ke rumah. Rumah Rusa yang terbakar dan si Elang berbohong kalau di dalam rumah itu ada emas yang sangat cantik dan si Cawi pun ingin pergi bersama Elang. Si Kancil ingin ikut bersamanya, tetapi Elang tidak membolehkan untuk ikut, lalu berangkatlah si Cawi dan Elang ke tempat rumah terbakar tersebut. Tanpa sepengetahuan Elang, si Kancil mengikuti mereka di belakang. Sampai di rumah tersebut, si Elang menyuruh Cawi untuk masuk ke rumah tersebut. Tetapi si Cawi ingin masuk bersama Elang, tetapi Elang menolaknya. Si Cawi pun masuk ke rumah itu dan ketika si Cawi masuk ternyata di dalam rumah tersebut terasa panas dan lengketlengket. Si Elang pergi dari tempat itu bersama Harimau.

Si Cawi pun meminta tolong dan tidak ada satu orang pun di tempat itu. Si Kancil pun datang untuk menolong si Cawi. Si Kancil mengambil tali dan menolong si Cawi. Kemudian badan Cawi sudah menjadi hitam, bahkan beberapa kali dicuci tidak bisa hilang. Si Cawi akan balas dendam kepada si Elang dan Harimau. Amanat: Janganlah menjadi teman yang bermuka dua baik di depan jahat di belakang.

Fakta dalam fabel ini yaitu, cawi merasa sesak nafas setelah masuk ke rumah yang terbakar itu dan badannya mulai menghitam. Hal 
ini jika dilakukan oleh manusia, pasti mereka juga merasakan apa yang sudah dialami Cawi. Imajinasinya yaitu Cawi bernyanyi dengan gembira, kalimat ini merupakan imajinasi karena hewan tidak bisa bicara apalagi bernyanyi.

Fakta dan imajinasi pada teks analisis fabel tersebut memiliki hubungan antara satu dengan yang lainnya yaitu dapat dilihat dari letak fakta yang terletak di resolusi karena Cawi terperangkap dalam rumah yang terbakar, sedangkan imajinasi terletak pada orientasi karena Cawi bernyanyi-nyanyi diawal cerita. Cerita di atas tidak dapat diterima oleh akal karena banyaknya tanya jawab sesama binatang yang logikanya tidak bisa diterima oleh akal pikiran dan hanya berisi imajinasi-imajinasi belaka.

\section{Ayam jantan dan Ikan Tongkol}

Pada suatu hari hiudplah seekor Ayam jantan dan Ikan Tongkol. Ayam jantan dan Ikan Tongkol tinggal di sebuah desa. Ayam jantan dan Ikan Tongkol sudah lama bersahabat. Ayam jantan tinggal di sebuah pohon yang sangat besar sedangkan Ikan Tongkol tinggal di sebuah danau yang tak jauh dari pohon yang besar itu.
Pada suatu hari Ayam jantan mengadakan pesta besar-besaran. Ayam jantan mengundang Ikan Tongkol untuk hadir ke pesta si Ayam jantan tersebut. Ikan Tongkol ragu-ragu untuk menerima undangan tersebut, tetapi Ayam jantan memaksa Ikan tongkol beserta rakyatnya. Akhirnya Ikan Tongkol menerima undangan dari Ayam jantan tersebut. "Tapi ada satu syaratnya", kata Ikan Tongkol. "Apa itu syaratnya?" Ayam jantan menjawab. "Pada saat fajar mau tiba, kau berkokok agar kami terbangun dan pergi menuju danau kembali”. Jika kau tidak menyanggupi permintaanku, aku juga tidak bisa hadir ke pestamu" kata Ikan Tongkol. "Oke", jawab Ayam jantan dengan tegas.

Pada suatu malam, tibalah pestanya mulai, Ikan Tongkol dan rakyatnya berbondong-bondong datang. Ayam jantan pun menyambut kedatangan ikan tongkol dan rakyatnya. Pesta pun semakin seru. Fajarpun sudah hampir tiba, Ayam Jantan lupa janjinya kepada Ikan Tongkol. Akhirnya ada seorang warga yang melihat Ikan Tongkol kelaparan di tepi danau. Kemudian warga yang melihatpun segera memanggil warga yang lain dan mengambil ikan tongkol yang kelaparan di tepi danau. Sejak itulah Ayam dan ikan tongkol bermusuhan.

Amanat yang bisa kita petik yaitu, jika kau memiliki janji tepatilah janji itu, jangan membuat orang menjadi membenci kita, padahal cuma gara-gara janji yang kita berikan kepadanya.

Fakta dalam fabel ini yaitu,

Ikan Tongkol menyuruh Ayam 
jantan untuk berkokok menjelang fajar, fakta di dunia nyata sebenarnya Ayam juga berkokok. Sedangkan imajinasinya yaitu Ayam jantan mengadakan pesta besar-besaran dan Ayam jantan memberikan undangan kepada Ikan tongkol.

Fakta dan imajinasi pada teks analisis fabel tersebut memiliki hubungan antara satu dengan yang lainnya yaitu dapat dilihat dari letak fakta dan imajinasi sama-sama terletak di struktur komplikasi, karena di komplikasi dijelaskan bahwa Ayam mengadakan pesta dan mengundang Ikan Tongkol, akan tetapi Ayam lupa berkokok saat fajar tiba. Hal ini menyebabkan Ikan Tongkol tertangkap oleh warga saat di tepi danau. Cerita di atas dapat diterima oleh akal pikiran karena Ayam berkokok menjelang fajar pertanda bahwa hari sudah mulai pagi. Sedangkan imajinasinya hanya digunakan agar fabel tersebut menarik untuk dibaca.

\section{Burung Gagak dan Burung Bangau}

Pada zaman dahulu disebuah hutan hiduplah sekelompok hewanhewan yang sangat banyak, mereka hidup dengan bahagia dan suka tolong menolong. Pada suatu hari hewan-hewan itu berkumpul dan membicarakan sesuatu. Ternyata, esok harinya mereka akan mengadakan acara gotong royong. Mereka bekerja bersama-sama dan saat itu di tepi sungai terlihat sesusatu yang bersinar. Rupanya ada dua ekor burung yaitu burung Gagak dan burung Bangau. Burung Gagak memiliki bulu yang indah dan mengkilau. Sedangkan Bangau memiliki bulu yang berwarna jelek tak terurus.

Pada saat itu Gagak dikerumuni hewan-hewan yang sedang bekerja tersebut. Sedangkan Bangau tak dihiraukan. Bangau pun merasa iri terhadap burung Gagak dan diapun merencanakan sesuatu. Dia akan merubah penampilannya dan akan memperburuk penampilan Gagak. Setelah selesai, merekapun pulang ke rumah. Setelah sampai di rumah, si Bangau mengobrol dengan si Gagak. "Gagak kenapa kau bisa secantik ini?", kata Bangau. Gagak pun menjawab, "Aku memakai ramuan khusus buatan ku sendiri". "Bolehkah aku meminta sedikit?" kata Bangau. "Boleh, tapi setelah memakainya, kembalikan kepadaku". Gagak pun memberikan ramuan tersebut. Bangau menaburkan ramuan tersebut dan ternyata Bangau menjadi cantik dan berkilau. Bangaupun keluar dan memamerkan kecantikan bulunya. Rupanya ada sang Kancil. Bolehkah saya meminta ramuanmu?" kata Kancil. "Tidak boleh, enak saja minta-minta", kata Bangau. "Dasar sombong, Gagak lebih cantik dan gagah", kata Kancil. Bangaupun merasa sakit hati dan iri kepada Gagak, diapun berniat 
merusak warna bulu Gagak, dengan cara mencampur semua ramuannya. Bangaupun pergi ke rumah Gagak dan berkata "ini ramuanmu", "Terima kasih Bangau" kata Gagak. Saat Gagak mendekat, Bangau pun menyiramkan ramuan tersebut. Gagak menjadi burung yang jelek. Bangau dan Gagak pun menjadi musuh.

Fakta dalam fabel ini yaitu, sekelompok hewan yang tinggal di Hutan. Hal ini merupakan fakta karena memang terbukti, kalau hutan itu tempat tinggalnya hewan. Kecuali hewan yang bisa dipelihara, mungkin akan dipelihara sendiri di rumah. Imajinasi dari fabel ini banyak mengandung perbincangan antara Gagak, Bangau, Harimau, dan Kancil seakan-akan mereka dapat berbicara. Hal ini tidak bisa diterima oleh logika dan sebenarnya hewan itu tidak dapat berbicara. Gagak bisa membuat ramuan sendiri, dan
Bangau meminta ramuan itu agar bulunya tampak indah seperti bulunya Gagak.

Hubungan fakta pada teks analisis fabel tersebut dapat dilihat dari letak fakta yang terdapat dalam orientasi, dibuktikan bahwa Gagak dan Bangau tinggal di hutan. Sedangkan imajinasinya terletak di komplikasi karena pembuatan ramuan yang dibuat Gagak dijelaskan dalam komplikasi dan mulai munculnya masalah dikarenakan adanya ramuan tersebut. Cerita di atas tidak dapat diterima oleh akal karena cerita ini hanya berupa impian-impian belaka yang merupakan imajinasi penulis. Seperti, Gagak yang bisa membuat ramuan sendiri, hal ini tidak logis karena burung di dunia nyata tidak bisa membuat ramuan sendiri.

\section{a. Perbandingan Hubungan Imajinasi dan Fakta dalam Pembuatan Fabel}

Tabel 1.

Perbandingan Hubungan Imajinasi dan Fakta (1)

\begin{tabular}{cccl}
\hline \multicolumn{4}{c}{ SMP 5 Muhammadiyah Surakarta } \\
\hline No. & \multicolumn{1}{c}{ Judul Fabel } & $\begin{array}{c}\text { Fakta } \\
\text { Terletak di }\end{array}$ & \multicolumn{1}{c}{$\begin{array}{c}\text { Imajinasi } \\
\text { Terletak di }\end{array}$} \\
\hline 1. & Kelinci dan Kura-kura & $\begin{array}{l}\text { Orientasi dan } \\
\text { Komplikasi }\end{array}$ & Orientasi \\
\hline 2. & Tikus dan Harimau & Komplikasi & Orientasi, \\
& & dan Resolusi & $\begin{array}{l}\text { Komplikasi, dan } \\
\text { Resolusi }\end{array}$ \\
\hline 3. & Gajah dan Semut & Orientasi & Komplikasi \\
\hline
\end{tabular}




\begin{tabular}{clll}
\hline 4. & Serigala dan Burung Merpati & Orientasi & Komplikasi \\
\hline 5. & Burung Gagak yang Cerdik & Orientasi & Resolusi \\
\hline 6. & Nasehat Burung Kenari & Orientasi & Resolusi \\
\hline 7. & $\begin{array}{l}\text { Penggembala Domba dan } \\
\text { Serigala }\end{array}$ & Komplikasi & Komplikasi \\
\hline 8. & Rusa dan Harimau & $\begin{array}{l}\text { Orientasi dan } \\
\text { Komplikasi }\end{array}$ & - \\
\hline 9. & Semut dan Merpati & $\begin{array}{l}\text { Orientasi dan } \\
\text { Komplikasi }\end{array}$ & $\begin{array}{l}\text { Komplikasi dan } \\
\text { Resolusi }\end{array}$ \\
\hline 10. & Si Belalang yang Sombong & $\begin{array}{l}\text { Orientasi dan } \\
\text { Komplikasi }\end{array}$ \\
\hline
\end{tabular}

Tabel 2.

Perbandingan Hubungan Imajinasi dan Fakta (2) SMP Muhammadiyah Pangkalan Bun

\begin{tabular}{rlll}
\hline No. & \multicolumn{1}{c}{ Judul Fabel } & $\begin{array}{c}\text { Fakta } \\
\text { Terletak di }\end{array}$ & $\begin{array}{c}\text { Imajinasi } \\
\text { Terletak di }\end{array}$ \\
\hline 1. & $\begin{array}{l}\text { Burung Cawi dan Burung } \\
\text { Elang }\end{array}$ & Resolusi & Orientasi \\
\hline 2. & Kisah Kancil yang Cerdik & Orientasi & Orientasi \\
\hline 3. & Ayam Jantan dan Ikan Tongkol & Komplikasi & Komplikasi \\
\hline 4. & $\begin{array}{l}\text { Burung Gagak dan Burung } \\
\text { Bangau }\end{array}$ & Orientasi & Komplikasi \\
\hline 5. & Kancil yang Cerdik dan Rusa & Orientasi & Komplikasi \\
& yang Sombong & Orientasi dan & Komplikasi \\
6. & Kambing yang Penakut & Resolusi & \\
\hline 7. & Si Burung Merpati tidak Tahu & Orientasi dan & Komplikasi \\
& Diri & Komplikasi & \\
\hline 8. & Kelinci dan Anjing Pemburu & Komplikasi & Komplikasi \\
\hline 9. & Buaya yang Serakah & Orientasi & Komplikasi \\
\hline 10. & Ayam yang Ceroboh & Orientasi & Resolusi \\
\hline 11. & & & \\
\hline
\end{tabular}


Berdasarkan fabel diatas dapat ditemukan bahwa fakta dan imajinasi tidak selalu ditemukan dalam salah satu struktur fabel saja. Fabel yang mempunyai dua fakta akan mempunyai dua letak struktur yang berbeda juga seperti pada tabel di atas. Misalnya, fabel yang berjudul Kelinci dan Kurakura, Tikus dan Harimau, Semut dan Merpati, dll. Sedangkan fabel yang berjudul Rusa dan Harimau dan Si Belalang yang Sombong merupakan fabel yang hanyaberisi fakta semua. Ada empat fabel yang mempunyai letak fakta dan imajinasi pada struktur yang sama yaitu fabel dengan judul Penggembala Domba dan Serigala terletak di struktur komplikasi, fabel Kisah Kancil yang Cerdik terletak di struktur orientasi, fabel Ayam Jantan dan Ikan Tongkol terletak di struktur komplikasi, yang terakhir fabel Kelinci dan Anjing Pemburu yang terletak di struktur komplikasi. Kemudian fabel yang berjudul Tikus dan Harimau mempunyai imajinasi yang terdapat pada tiga struktur fabel yaitu orientasi, komplikasi, dan resolusi. Fabel dengan judul Semut dan Merpati juga mempunyai imajinasi yang terletak di dalam dua struktur yang berbeda yaitu di struktur komplikasi dan resolusi.
Hasil penelitian yang dilakukan oleh Wiguna (2018) mempunyai persamaan dengan hasil penelitian ini yaitu sama-sama meneliti tentang tokoh, latar dan amanat dalam cerita. Perbedaannya penelitian ini mengkaji tentang hubungan imajinasi dan fakta dalam fabel, sedangkan penelitian Wiguna tidak meneliti hubungan antara keduanya. Fokus penelitian Wiguna mengkaji tentang unsur intrinsik cerpen. Fokus penelitian ini mengkaji tentang struktur fabel.

Hasil penelitian yang dilakukan oleh Safiatuddin (2018) mempunyai persamaan dengan penelitian ini yaitu teridentifikasi beberapa siswa yang sudah mampu menulis fabel berdasarkan strukturnya. Populasi yang diteliti Safiatuddin berjumlah 35 siswa kelas VIII, sedangkan penelitian ini hanya menggunakan 20 siswa. Penelitian Safiatuddin hanya menggunakan data dari sekolahan, sedangkan penelitian ini menggunakan 2 sekolah yang berbeda. Fokus penelitian ini dengan penelitian Safiatuddin sama-sama menganalisis struktur orientasi, komplikasi, resolusi, dan koda. Perbedaan penelitian ini mengkaji tentang hubungan imajinasi 
dan fakta, sedangkan penelitian Safiatuddin tidak mengkaji keduanya. Penelitian yang dilakukan oleh Sudiasa, Rasna dan Indriani (2015) mempunyai persamaan dengan penelitian ini yaitu teridentifikasi beberapa siswa yang sudah mampu menulis fabel dengan baik. Populasi yang diteliti Sudiasa, dkk berjumlah 27 siswa kelas VII, sedangkan penelitian ini hanya menggunakan 20 siswa. Fokus penelitian Sudiasa ditinjau dari struktur gramatikal, morfologi, dan sintaksis. Fokus penelitian ini mengenai analisis struktur fabel yang dihubungkan dengan fakta dan imajinasi.

Hasil dari penelitian yang dilakukan Bahri (2014) mempunyai persamaan dengan hasil penelitian ini sama-sama menemukan tentang struktur fabel yang sudah sesuai dan dihubungkan dengan fakta serta perilaku tokoh. Tokoh dalam penelitian Bahri ada Godek dan Tuntel yang diambil dari bahasa Sasak memiliki arti Monyet dan Katak. Selain itu, persamaannya samasama dihubungkan dengan perilaku tokoh dalam pengungkapan fakta. Perbedaan penelitian ini menggunakan nama-nama hewan nasional, tidak diambil dari nama bahasa daerah seperti penelitian yang dilakukan oleh Bahri.
Penelitian Bahri dikaitkan dengan perilaku masyarakat Sasak sesuai dengan tingkat sosial. Penelitian ini selain dihubungkan dengan fakta, juga dihubungkan dengan imajinasi dalam fabel.

Hasil penelitian yang dilakukan oleh Bhattacharya (2019) mempunyai persamaan dengan hasil penelitian ini yaitu sama-sama menggunakan teks fabel yang dihubungkan dengan fungsi alam terhadap kehidupan makhluk. Penelitian Bhattacharya menerapkan agar anak-anak membaca bacaan informatif yang bermanfaat. Perbedaan penelitian Bhattacharya dengan penelitian ini tidak membahas struktur wacana fabel secara detail. Sedangkan, penelitian ini mengkaji tentang struktur fabel dan dihubungkan dengan fakta dan imajinasi.

Hasil penelitian yang dilakukan oleh Frimasary (2015) mempunyai persamaan dengan hasil penelitian ini yaitu siswa mampu memahami suatu cerita dan menuangkan idenya dalam bentuk fabel. Penelitian Frimasary tidak mengkaji struktur wacana fabel secara rinci dan fokus penelitiannya terletak pada pemahaman siswa dalam membaca fabel. Fokus penelitian ini mengkaji tentang struktur fabel secara rinci dan 
dihubungkan dengan fakta serta imajinasi fabel.

Hasil penelitian yang dilakukan oleh Ranabumi, dkk (2017) mempunyai persamaan dengan penelitian ini yaitu sama-sama meningkatkan keterampilan menulis fabel. Penelitian Ranabumi menggunakan model pembelajaran Time Token dan media video, sedangkan penelitian ini hanya menggunakan metode demonstrasi saat penyampaian materi. Fokus penelitian Ranabumi terletak pada prestasi belajar keterampilan menulis fabel. Fokus penelitian ini mengkaji tentang struktur fabel dan dihubungkan dengan imajinasi serta fakta fabel.

Hasil penelitian yang dilakukan oleh Irshad dan Ahmed (2015) mempunyai persamaan dengan penelitian ini yaitu sama-samamengkaji tentang struktur wacana fabel. Fokus penelitian Irshad dan Ahmed terletak pada cara membuat cerita melalui premis, tema, dll. Sedangkan penelitian ini fokus pada hubungan imajinasi dan fakta fabel.

Hasil penelitianyang dilakukan oleh Rahim dan Maila (2012) mempunyai persamaan dengan penelitian ini yaitu sama-sama berhubungan dengan fakta yang masih ada kaitannya dengan nilai-nilai moral pendidikan atau karakter melalui fabel. Perbedaan penelitian Rahim dan Maila dengan penelitian ini tidak membahas struktur wacana fabel secara rinci. Fokus penelitian Rahim dan Maila terletak pada peran guru dalam menyampaikan pesan cerita yang berupa nilai-nilai moral sebagai pendidikan moral di taman kanak-kanak. Sedangkan, fokus penelitian ini terletak pada struktur fabel dan hubungan fakta serta imajinasi fabel yang dibuat oleh siswa SMP bukan TK.

\section{Penutup}

Berdasarkan hasil penelitian dan pembahasan mengenai hubungan imajinasi dan fakta dalam struktur fabel, penulis menyimpulkan hasil bahwa semua fabel yang ada tersusun dari fakta dan opini di setiap isi karangan. Fabel tersebut memiliki hubungan antara imajinasi dan fakta yang terdapat pada 4 fabel yang mempunyai letak fakta dan imajinasi yang sama yaitu terletak di komplikasi ada 3 fabel, dan di orientasi ada 1 fabel. Fakta yang terbanyak dari karangan siswa SMP 5 Muhammadiyah terdapat di struktur orientasi ada 8 , fakta di struktur komplikasi ada 6, dan fakta di struktur resolusi hanya ada 1. Fakta 
yang terbanyak dari karangan siswa SMP Muhammadiyah Pangkalan Bun terdapat di struktur orientasi ada 7 fabel, fakta di struktur komplikasi ada 3, dan fakta di struktur resolusi hanya ada 2 . Imajinasi yang terbanyak dari karangan siswa SMP 5 Muhammadiyah terdapat di struktur komplikasi ada 5, imajinasi di stuktur orientasi ada 2, dan imajinasi di struktur resolusi ada 4. Imajinasi yang terbanyak dari karangan siswa SMP Muhammadiyah Pangkalan Bun terdapat di struktur komplikasi ada 7 fabel, fakta di struktur orientasi ada 2 , dan fakta di struktur resolusi hanya ada 1. Kemudian fabel yang imajinasinya terletak pada 3 struktur ada 2 fabel, selain itu ada 2 fabel yang hanya berisi fakta semua tidak ada imajinasinya.

\section{Daftar Pustaka}

Al-Ma'ruf, Ali Imron dan Nugrahani, F. 2017. Pengkajian Sastra: Teori dan Aplikasi. Surakarta: CV. Djiwa Amarta Press.

Arsyad, A., Syam, R., \& Ardat, A. (2017). "Deskripsi Kemampuan Koneksi Matematis pada Materi Sistem Persamaan Linear Dua Variabel Ditinjau dari Gaya Kognitif Siswa SMP Kelas IX". Issues in Matematics Education, 1 (1), 53-59.

Bahri, S. (2014). "Analisis Struktural Fabel Tegodek Dait Tetuntel: Representasi Perilaku Dalam
Masyarakat Sasak". Mabasan, 8 (2), 164-176.

Bhattacharya, N. (2019). "Environmental Consciousness In Indian Fables: How

and What The Pañcatantra Can Teach Our Children". Environmental Issues: Approaches and Practices, 1 (1), 47-51.

Halida, S. (2011). "Kemampuan Menentukan Struktuk Teks Cerita Fabel Siswa Kelas VIII SMP Negeri 2 Limbong Kabupaten Luwu Utara". Jurnal Onoma, 2 (1), 41-54.

Frimasary, A.E. (2015). "Using Short Story to Improve Student's Reading Comprehension (A Study At The Second Year Student Of Smpn 2 Kota Bengkulu)". Journal of Linguistics and Language Teaching, 2 (2), 1-8.

Irshad, A., \& Ahmed, M. (2015). "The Structural Analysis Of "Take Pity": A Short Story by Bernard Malamud". European Journal of English Language, Linguistics and Literature, 2 (1), 26-31.

Nasution, Y.A. (2018). "Peningkatan Menulis Teks Fabel melalui Model Pembelajaran Media Gambar". Jurnal Ilmiah Pendidikan Bahasa dan Sastra Indonesia, 1 (1), 18-29.Genjiro". Jurnal Japanese Literature, 2 (2), 1-10.

Nurgiyantoro, Burhan. 2005. Sastra Anak. Yogyakarta: Gadjah Mada University Press. 
Hubungan Imajinasi dan Fakta dalam...

Pradopo, R.D., \& dkk. (2003). Metodologi Penelitian Sastra. Yogyakarta: Hanindita.

Putri, A.T. (2017). "Struktur dan Makna Cerpen Si Rubbah Gong Karya Niimi Nankichi". JAPANOLOGY, 5 (2), 215-225.

Rahardjo, M. (2010, Oktober 15). Triangulasi dalam Penelitian Kualitatif [Weblog post]. Retrieved from https://www.uinmalang.ac.id/r/101001/triangulasidalam-penelitian-kualitatif.html

Rahim, H., \& Maila D,H,R. (2012). "The Use of Stories as Moral Education for Young Children". International Journal of Social Science and Humanity, 2 (6), 454-458.

Ranabumi, R., Rohmadi, M., \& Subiyantoro, S. (2016). "Improving Students' Writing Short Story Skill through Time Token Learning and Video Media on grade VII Junior High School". Journal of Education and Learning, 11 (4), 439-445.

Safiatuddin, Ramli, \& Subhayni. (2018). "Kemampuan Siswa Kelas VIII SMP Negeri 13 Banda Aceh menyusun Teks Cerita Fabel". JIM PBSI, 3 (3), 231-239.

Sibua, S., \& Iskandar, F. (2016). "Kemampuan Mengidentifikasi Fakta dan Opini dalam Teks Surat Kabar Melalui Kegiatan Membaca Intensif Siswa Kelas VIII SMP Negeri 4 Kota Ternate". Jurnal Pendidikan, 14(1), 355-363.

Sudiasa, I.W., Rasna, I.W., \& Indriani, M.S. (2015). "Kemampuan Menulis Cerita Fabel dalam Pembelajaran Bahasa Indonesia Siswa Kelas VIII
SMPN 6 Singaraja: Sebuah Kajian Struktur Gramatikal”. e-Journal Universitas Pendidikan Ganesha, 3 (1), 1-10.

Syamsuddin \& Damaianti, V.S. (2006). Metode Penelitian Pendidikan Bahasa. Bandung: PT Remaja Rosdakarya.

Wiguna I.G.M., Mandra, I.W., \& Saputra, I.M.D. (2018). "Analisis Struktur Intrinsik Cerpen Luh Bulan Karya Ibw Widiasa Keniten". Jurnal Pendidikan Agama, Bahasa dan Sastra Agama, 8 (2), 132-138. 